Influence of landscape features on urban land surface temperature: scale and neighborhood effects

Shi, Yi; Liu, Shuguang; Yan, Wende; Zhao, Shuqing; Ning, Ying; Peng, Xi; Chen, Wei; Chen, Liding; Hu, Xijun; Fu, Bojie; Kennedy, Robert ; Lv, Yihe; Liao, Juyang; Peng, Chungliang; Rosa, Isabel; Roy, David ; Shen, Shouyun; Smith, Andy; Wang, Chen; Wang, Zhao; Xiao, Li; Yang, Lu ; Yuan, Wenping ; Yi, Min; Zhang, Hankui; Zhao, Meifang; Zhu, Yu; Xiao, Jingfeng

\title{
Science of the Total Environment
}

DOI:

https://doi.org/10.1016/j.scitotenv.2021.145381

Published: 01/06/2021

Peer reviewed version

Cyswllt i'r cyhoeddiad / Link to publication

Dyfyniad o'r fersiwn a gyhoeddwyd / Citation for published version (APA):

Shi, Y., Liu, S., Yan, W., Zhao, S., Ning, Y., Peng, X., Chen, W., Chen, L., Hu, X., Fu, B., Kennedy, R., Lv, Y., Liao, J., Peng, C., Rosa, I., Roy, D., Shen, S., Smith, A., Wang, C., ... Xiao, J. (2021). Influence of landscape features on urban land surface temperature: scale and neighborhood effects. Science of the Total Environment, 771, [145381].

https://doi.org/10.1016/j.scitotenv.2021.145381

\section{Hawliau Cyffredinol / General rights}

Copyright and moral rights for the publications made accessible in the public portal are retained by the authors and/or other copyright owners and it is a condition of accessing publications that users recognise and abide by the legal requirements associated with these rights.

- Users may download and print one copy of any publication from the public portal for the purpose of private study or research.

- You may not further distribute the material or use it for any profit-making activity or commercial gain

- You may freely distribute the URL identifying the publication in the public portal ?

Take down policy

If you believe that this document breaches copyright please contact us providing details, and we will remove access to the work immediately and investigate your claim. 


\section{Influence of landscape features on urban land surface temperature: scale and neighborhood effects}

Yi Shi ${ }^{1}$, Shuguang Liu ${ }^{1 *}$, Wende Yan ${ }^{1}$, Shuqing Zhao ${ }^{2}$, Ying Ning ${ }^{1}, X_{i}$ Peng $^{1}$, Wei Chen ${ }^{1}$, Liding Chen ${ }^{3}$, Xijun $\mathrm{Hu}^{3}$, Bojie $\mathrm{Fu}^{3}$, Robert Kennedy ${ }^{5}$, Yihe $\mathrm{Lv}^{3}$, Juyang Liao ${ }^{6}$, Chunliang Peng $^{6}$, Isabel MD Rosa ${ }^{7}$, David Roy ${ }^{8}$, Shouyun Shen ${ }^{3}$, Andy Smith ${ }^{7}$, Cheng Wang ${ }^{9}$, Zhao Wang $^{1}$, Li Xiao ${ }^{1}$, Jingfeng Xiao ${ }^{10}$, Lu Yang ${ }^{2}$, Wenping Yuan ${ }^{11}$, Min Yi ${ }^{12}$, Hankui Zhang ${ }^{13}$, Meifang Zhao ${ }^{1}$, Yu Zhu ${ }^{1}$

${ }^{1}$ College of Life Science and Technology, and National Engineering Laboratory for Applied Technology in Forestry \& Ecology in South China, Central South University of Forestry and Technology, Changsha, China 410004

${ }^{2}$ Peking University, Beijing, China 100871

${ }^{3}$ Center for Ecological Research, Chinese Academy of Sciences, Beijing, China 100085

${ }^{4}$ College of Landscape Architecture, Central South University of Forestry and 16 Technology, Changsha, China 410004

${ }^{5}$ Geography, Environmental Sciences, and Marine Resource Management, Oregon 18 State University, Corvallis, OR 97331

${ }^{6}$ Hunan Forest Botanical Garden, Changsha, China 410116

${ }^{7}$ School of Natural Sciences, Bangor University, Gwynedd, UK LL57 2UW

${ }^{8}$ Department of Geography, Environment, and Spatial Sciences, Michigan State 22 University, East Lansing, MI 48824

${ }^{9}$ Chinese Academy of Forestry, Beijing, China 100091

${ }^{10}$ Earth Systems Research Center, Institute for the Study of Earth, Oceans, and Space, 25 University of New Hampshire, Durham, NH 03824

${ }^{11}$ School of Atmospheric Sciences, Guangdong Province Key Laboratory for Climate

Change and Natural Disaster Studies, Zhuhai Key Laboratory of Dynamics Urban 28

Climate and Ecology, Sun Yat-sen University, Zhuhai, China 510245

${ }^{12}$ Ecology and Environment Department of Hunan Province, Changsha, China 410014

${ }^{13}$ Department of Geography and Geospatial Sciences, and the Geospatial Sciences

Center of Excellence, South Dakota State University, Brookings, SD 57007

* Corresponding Author: Shuguang Liu (shuguang.liu@yahoo.com), 410004, 
Abstract

Higher land surface temperature (LST) in cities than its surrounding areas presents a major sustainability challenge for cities. Adaptation and mitigation of the increased

LST require in-depth understanding of the impacts of landscape features on LST. We studied the influences of different landscape features on LST in five large cities across China to investigate how the features of a specific urban landscape (endogenous features), and neighboring environments (exogenous features) impact its LST across a continuum of spatial scales. Surprisingly, results show that the influence of endogenous landscape features $\left(E_{\text {endo }}\right)$ on LST can be described consistently across all cities as a nonlinear function of grain size $\left(g_{s}\right)$ and neighbor size $\left(n_{s}\right)\left(E_{\text {endo }}=\beta n_{s} g_{s}^{-0.5}\right.$, where $\beta$ is a city-specific constant) while the influence of exogenous features $\left(E_{\text {exo }}\right)$ depends only on neighbor size $\left(n_{s}\right)\left(E_{\text {exo }}=\gamma-\varepsilon n_{s}{ }^{0.5}\right.$, where $\gamma$ and $\varepsilon$ are city-specific constants). In addition, a simple relationship describing the relative strength of endogenous and exogenous impacts of landscape features on LST was found ( $E_{\text {endo }}>$ $E_{\text {exo }}$ if $n_{s}>\mathrm{kg}_{s}{ }^{2 / 5}$, where $k$ is a city-specific parameter; otherwise, $E_{\text {endo }}<E_{\text {exo }}$ ). Overall, vegetation alleviates $40 \%-60 \%$ of the warming effect of built-up while surface wetness intensifies or reduces it depending on climate conditions. This study reveals a set of unifying quantitative relationships that effectively describes landscape impacts on LST across cities, grain and neighbor sizes, which can be instrumental towards the design of sustainable cities to deal with increasing temperature.

Keywords: Urban heat island; Neighbor landscape features; Scale dependence; 
Landscape composition; Ridge regression

\section{Introduction}

The urban heat island (UHI), referring to the elevated land surface temperature (LST) in urban environments in comparison with that in the surrounding rural areas, has become a major sustainability challenge for cities because of its various adverse impacts on the environment and urbanites(Oke, 1982; Swamy et al., 2017). Some of the major UHI consequences are aggravated water and energy consumption ( $\mathrm{Li}$ et al., 2019c), exacerbated health-harming heat-stress (Patz et al., 2005; Wang et al., 2019a), and secondary air pollution from photochemical reaction (Swamy et al., 2017), among others. It is potentially possible to mitigate the UHI impact through the composition and patterns of landscape features including vegetation, impermeable surfaces, and water bodies since UHI is resulted from the differences in their thermal properties (Jamei et al., 2019; Zhou et al., 2013). Although some "coarse-grained" theories based on the principle of energy and radiation transmission provide a good basis for understanding broad-scale UHI physical logics synoptically (Manoli et al., 2019), they have limited applicability to fine- to local-scale landscape manipulations. Urban planners and decision-makers urgently need improved knowledge to help them develop adaptation strategies to climate change as cities expand (Bai et al., 2018). Understanding the influences of various landscape features on UHI and its dependence on spatial scale is critical for developing sustainable cities by integrating 
infrastructure to create environmental and economic efficiency while improving the overall quality of life (Nam and Pardo, 2011; Ramaswami et al., 2016; Ziter et al., 2019). These influences, aka UHI sensitivities to "fine-grained" urban landscapes, are not well understood and a wide range of disparities exist. For example, in summer, a $10 \%$ increase in greenspace would result in a decrease of $3.4^{\circ} \mathrm{C}$ in LST in Phoenix, Arizona (Connors et al., 2012), but only $2^{\circ} \mathrm{C}$ in Manchester, UK (Skelhorn et al., 2014), and $1.1{ }^{\circ} \mathrm{C}$ in Delhi, India (Pramanik and Punia, 2019). Similarly, every $10 \%$ increase in the built-up proportion would increase LST by $3.2^{\circ} \mathrm{C}$ in Phoenix, Arizona (Connors et al., 2012), but only by $0.45^{\circ} \mathrm{C}$ in the Baltimore-DC metropolitan area (Tang et al., 2017). Those inconsistent sensitivities of LST bring challenges to city designers and managers to improve energy efficiency, district heating and cooling.

Although the exact reasons for this inconsistency remain unknown, two possible explanations exist. First, it is speculated that the interplay among landscape features across a continuum of scales, following certain scaling relationships, might be responsible (Nill et al., 2019; Wang et al., 2019b). To find and quantify the intrinsic influence of landscape features on LST, we must realize that cities are complex systems with many interactive (Behl and Mangharam, 2016), interdependent landscape components whose intertwined intrinsic influences on LST must be untangled using appropriate methods. Meanwhile, the environmental stability of a landscape and influence intensity of its neighborhood are functions of features on a range of spatial scales from sub-meters to thousands of meters (Chun and Guldmann, 
2014). This scale dependency has been described as one of the key challenges in addressing urban environmental changes (Landauer et al., 2018). Although it is understood that both own and neighboring landscapes affect the LST of a given urban land parcel (Chun and Guldmann, 2014), previous studies focus mainly on the influences of own environment (i.e., endogenous effect) with little attention on the influences of its neighboring landscapes (i.e., exogenous effect) (Guo et al., 2019;

Zhou et al., 2017). The relative influence of endogenous and exogenous effects and its variation with spatial scale are not clear, calling for systematic studies investigating the scaling rules of these effects across scales. Second, the inconsistency could also be caused by cross-city differences in biophysical conditions. Some paired comparative studies have shown that the effects of landscape features cross cities varied with climate zones (Rasul et al., 2015; Xiao et al., 2018). To improve our understanding of the cross-city variability, we must conduct comprehensive studies with multiple cities covering a wide range of vegetation conditions, urban landscape features, and climate regimes (Best and Grimmond, 2016; Taleghani et al., 2019; Theeuwes et al., 2017).

Here, we studied the endogenous and exogenous effects of landscape features on LST in five large cities (i.e., Beijing, Shanghai, Changsha, Chongqing, and Changchun) across China (Fig. 1). A range of grid/grain sizes (90-, 360-, 630-, and 900-m length scale) and neighborhood sizes $(3 \times 3,5 \times 5,7 \times 7$, and $9 \times 9$ grid cells) were used to investigate the change of the endogenous and exogenous effects across scales (Fig. 2). The research aims of this study were to: (1) compare the influences of 
different landscape characteristics on LST; (2) investigate the endogenous and exogenous landscape effects on LST and their scale dependence; (3) examine the commonality and differences of endogenous and exogenous landscape effects across cities.

\section{Data and Methods}

\subsection{Study sites}

Five major cities (i.e., Beijing, Changchun, Shanghai, Changsha, and Chongqing) across China were selected to investigate the geographic variations of UHI and the endogenous and exogenous impacts of landscape features on LST as a function of grain and neighbor sizes (Fig. 1). These cities were at least provincial capitals, located in the North, Northeast, East, Central-south, and Southwest China, respectively. No cities were selected from the Northwest region because no obvious UHI was found there according to a previous study (Zhou et al., 2014). The climate in the East, Central-south, and Southeast China typically has hot and rainy summers. In contrast, North and Northeast China have relatively subhumid/semiarid-temperate and typical humid-cold climate in summer, respectively (Shi et al., 2014). In addition, the vegetation types of these five cities also have obvious north-south differences, which are greatly affected by climate. Specifically, the regional vegetation in Beijing and Changchun is dominated by temperate mixed deciduous broad-leaved forests, whereas that in Shanghai, Chongqing, and Changsha is dominated by subtropical evergreen broad-leaved forests. 


\subsection{Data}

UHI studies mainly used two data sources: ground-based measurements (Shaker et al., 2019; Ziter et al., 2019) and remotely sensed data (Manoli et al., 2019; Zhou et al., 2017). Compared with ground-based measurement, remotely sensed data have been used frequently in urban thermal studies due to easy access to cross-regional images. In this study, we used Landsat-8 Thematic Mapper (TM) images with a spatial resolution of $30 \mathrm{~m}$ acquired around 11 AM local time in July of 2017. If no cloudless images available in July of 2017, images in July of 2016 or 2018 were used. The TM data for Beijing, Changchun, Shanghai, Changsha, and Chongqing were acquired on July 10, 2017 (row 32/ path 123), July 4, 2016 (row 30/ path 118), July 23, 2017 (row 38/ path 118), July 26, 2017 (row 41/ path 123), July 26, 2016 (row 39/ path 128), respectively.

\subsubsection{Landscape features calculation}

To investigate the impacts of landscape features, proportion of vegetation (PV), normalized difference built-up index (NDBI), modified normalized difference water index (MNDWI) and wetness index (Wetness) were calculated from surface reflectance to represent surface landscape condition (Gautam et al., 2015a; Huang et al., 2002; Kim, 2013). MNDWI is often used to extract open water features while Wetness index is more sensitive to soil and plant moisture, and we used both in our study. 
The PV has been extensively used to reflect the percentage of vegetative ground cover (Dwivedi et al., 2018; Neinavaz et al., 2020). It is calculated based on the normalized difference vegetation index (NDVI) (Rouse et al., 1974):

$$
\mathrm{PV}=\left[\left(\mathrm{NDVI}-N D V I_{\min }\right) /\left(N D V I_{\max }-N D V I_{\min }\right)\right]^{2}
$$

Where $N D V I_{\min }(0.05)$ and $N D V I_{\max }(0.7)$ are the thresholds of soil and vegetation pixel. The NDVI is calculated as (Xu and Guo, 2014):

$$
\mathrm{NDVI}=(\mathrm{NIR}-\mathrm{Red}) /(\mathrm{NIR}+\mathrm{Red})
$$

Where NIR is the near infrared band, Red is a red band.

The NDBI is effective at identifying built-up area from medium-resolution satellite imagery (Chen et al., 2006; Guha et al., 2018). It is computed as a ratio involving the short-wave infrared band (SWIR1) and the near infrared band (NRI):

$$
\mathrm{NDBI}=(\mathrm{SWIR} 1-\mathrm{NIR}) /(\mathrm{SWIR} 1+\mathrm{NIR})
$$

Xu proposed the MNDWI, a more effective index than the NDWI in distinguishing water in urban areas (Xu, 2006). Water surface is often mixed with built-up land with NDWI while, after substituting the NIR band with SWIR1 band, MNDWI could enhance water presence and more accurately extract open water features than the NDWI (Gautam et al., 2015b). Specifically, the MNDWI is calculated as: 


$$
\text { MNDWI }=(\text { Green }- \text { SWIR1 }) /(\text { Green }+ \text { SWIR1 })
$$

Where Green is a green band, and MNDWI ranges from -1 to 1 , and positive values represent water bodies.

Wetness, a Landsat Thematic Mapper(TM) Tasseled Cap feature, is characterized by differentials between the sum of the visible and near-infrared bands and the longerinfrared bands (Crist et al., 1984). The longer-infrared TM bands have been corroborated to be sensitive to soil and plant moisture, therefore effective in representing wetness. The Wetness index can be calculated as follows using Landsat OLI data (Baig et al., 2014):

Wetness $=0.1511 \times$ Blue $+0.1973 \times$ Green $+0.3283 \times$ Red $+0.3407 \times$ NIR $-0.7117 \times$ SWIR $1-0.4559 \times$

SWIR2

Where Blue is a blue band, SWIR1 and SWIR2 are the short-wave infrared bands (TM band 6 and band 7), respectively.

\subsubsection{Land surface temperature (LST)}

LST was derived from the thermal infrared band 10 (TIRS1) of the Landsat- 8

Thermal Infrared Sensor (TIRS) using the classic radiative transfer equation (RTE) owing to its higher accuracy than a single-channel algorithm and the split-window algorithm (Yu et al., 2014). First, the digital number (DN) of TIRS band 10 was 
converted to absolute radiation brightness, and then the transformation of RTE was used to calculate black-body radiation brightness as follows (Zhou et al., 2012):

$$
\mathrm{TS}=[\mathrm{L} \lambda-L \uparrow-\tau(1-\varepsilon) L \downarrow] / \tau \varepsilon
$$

Where $\mathrm{TS}\left(\right.$ watts $\left./ m 2 *{ }^{\prime} r * \mu m\right)$ is the black-body radiation, $\mathrm{L} \lambda($ watts $/ m 2 * s r * \mu m)$ is the spectral radiation brightness of band $10, \tau$ is the transmittance of thermal infrared bands in the atmosphere, $L \uparrow\left(\right.$ watts $\left./ m 2 *_{s} r * \mu m\right)$ and $L \downarrow($ watts $/ m 2 * s r * \mu m)$ are the brightness of upward and downward radiation in the atmosphere (http://atmcorr.gsfc.nasa.gov), respectively, and $\varepsilon$ is land surface emissivity calculated from vegetation proportion (PV) (Sobrino et al., 2004):

$$
\varepsilon=(0.004 \times \mathrm{PV})+0.986
$$

Finally, LST was calculated from black-body radiation brightness using the Plank function (Chander et al., 2003):

$$
\mathrm{T}=K 2 / \ln \left(\frac{K 1}{T S}+1\right)-273
$$

Where $\mathrm{T}$ is land surface temperature $\left({ }^{\circ} \mathrm{C}\right), K 1=774.89 \mathrm{watts} / \mathrm{m} 2 * s{ }^{*} \mu \mathrm{m}, K 2=$ $1321.08 K$ (values were obtained from the metadata file).

\subsection{Statistical analysis}

Landscape features such as proportions and spatial form of green space have strong impacts on the LST of a given land parcel, and the impacts can be categorized into endogenous and exogenous (Chun and Guldmann, 2014). The endogenous 
impact represents the impacts of a grid cell's own landscape features, and the exogenous impact is from its neighborhood landscape features. To investigate the endogenous, exogenous, and their joint impacts of landscape features on LST, we analyzed the relationships between landscape features and LST at multiple spatial scales with various grid cell sizes and neighborhood ranges (Fig. 2). Specifically, four grid cell sizes (i.e., 90 m, 360 m, 630 m, and 900 m) were used. For each grid cell size, we analyzed the exogenous impacts of landscape features within four classes of the neighborhood: $3 \times 3,5 \times 5,7 \times 7$, and $9 \times 9$ grids.

To estimate the impacts of landscape features on LST, the mean LST of a grid cell was the dependent variable, and the independent variables (i.e., landscape features) were divided into two categories: endogenous characteristics or the characteristics of a given grid cell, and exogenous features or the landscape features of its neighborhood. The endogenous variables used in this study included PV, NDBI, MNDWI, and Wetness, and the exogenous features were the mean, maximum, and range of PV, NDBI, MNDWI, and Wetness in the neighborhood, the mean, maximum and range value of exogenous features denote absolute conditions (average and highest) and relative conditions (range or heterogeneity) of exogenous landscape features.

The Pearson correlation, the most common method used to calculate the linear correlation between two variables without considering the interference of other factors (Lee Rodgers and Nicewander, 1988), was used first to explore the relationships 
between LST and landscape features across spatial scales. Then, the partial correlation coefficients were calculated to investigate the strength of linear relationships between LST and other landscape features, by holding the effects of some variables constant (Geladi and Kowalski, 1986).

The standardized coefficients (beta weights) of linear and ridge regression analyses were used to explore the sensitivity of LST to landscape features (i.e., the impacts of landscape features on LST). We first used the simple ordinary least squares (OLS) linear regression to quantify the influence strength of individual landscape features. The slope of the simple linear regression between LST and any given variable was referred as the manifested sensitivity of the LST. The use of the phrase "manifested sensitivity" here was to reflect the fact that this sensitivity manifests not only the relationship between the independent and dependent variables but also the (hidden) influences of other variables. It is different from the "intrinsic sensitivity", described below, where the influences of other independent variables are removed.

OLS multiple linear regression can potentially be used to examine the effects of independent variables. We first tested the applicability of the OLS multiple linear regression using the variance inflation factor (VIF) (O'brien, 2007) and found that VIF was higher than 10, suggesting that the OLS multiple linear regression was not applicable due to the existence of strong multicollinearity among independent variables. Subsequently, we used the ridge regression, a regression method for 
collinear data analysis (Muniz and Kibria, 2009), to estimate the intrinsic sensitivities of the independent variables, which are defined by the regression coefficients (i.e., LST change as a result of every 1 unit change in a given landscape feature index). In essence, ridge regression is an improved OLS estimation method, penalizing large coefficients through the L2 Norm, with:

$$
\begin{array}{cc}
m & n \\
f(w)=\sum_{j=1}\left(y_{i}-x_{i}\right. & \left.r_{w i}\right)^{2}+\lambda \sum_{j=1}^{2}
\end{array}
$$
cross validation approach, and we chose the $\lambda$ at which the mean squared error (MSE) 264 was within one standard error of the minimal MSE as the best estimator of $\lambda$.

Variance partition is an effective way to explain the relative contributions of independent variables to the variance of LST (Anderson and Cribble, 1998). In this study, the LST variance was partitioned into the following four parts, following the procedures outlined in (Peres-Neto et al., 2006), to elucidate the endogenous, exogenous, and their joint impacts of landscape features on LST: (1) endogenous effect of the grid cell's own characteristics, (2) exogenous effect of neighborhood 

unexplained variance.

274 packages were used: the "glmnet" for ridge regression, and the "vegan" for variance

275 partitioning.

\section{Results}

\subsection{Variation of LST and landscape features in cities}

The characteristics of the LST in each city are shown in Fig. S1-S5 and Table S1. Although the LST values were not strictly comparable across cities because the images were taken at different points in time, the LST observations in each city were internally consistent. Therefore, the overall features of LST presented here should provide some synoptic overview of the LST distribution in the cities. The mean LST was $42.99{ }^{\circ} \mathrm{C}$ (range $26.13-55.77^{\circ} \mathrm{C}$ ) in Beijing, $42.83{ }^{\circ} \mathrm{C}$ (range $24.93-62.12{ }^{\circ} \mathrm{C}$ ) in Chongqing, $40.89^{\circ} \mathrm{C}$ (range $27.52-61.14^{\circ} \mathrm{C}$ ) in Changsha, $40.2^{\circ} \mathrm{C}$ (range 24.77-60.38 ${ }^{\circ} \mathrm{C}$ ) in Shanghai, and $38.01{ }^{\circ} \mathrm{C}$ (range $24.95-57.05{ }^{\circ} \mathrm{C}$ ) in Changchun. The frequency distributions of LST were slightly left-skewed in each of the five cities.

The frequency distributions of proportion of vegetation (PV) and normalized difference built-up index (NDBI) values were right- and left-skewed, respectively, for all five cities (Figs. S1-S5). However, PV and NDBI values were significantly different among the five cities (Table S1). The mean values of PV in descending order 
were Changsha (0.253), Chongqing (0.246), Changchun (0.225), Shanghai (0.211)

and Beijing (0.201). NDBI decreased from Changsha (-0.076), Changchun (-0.078), Beijing (-0.083), Shanghai (-0.091), to Chongqing (-0.093). In addition, the mean modified normalized difference water index (MNDWI) data presented unimodal distributions in Beijing and Changchun, and bimodal distributions in Shanghai, Chongqing, and Changsha (Figs. S1-S5). The MNDWI and Wetness in similar descending order were Shanghai (-0.070, -1079), Chongqing (-0.085, -1517), Beijing (-0.085, -1615), Changchun (-0.108, -2141), and Changsha $(-0.474,-2147)$ (Table S1).

\subsection{Correlations between LST and landscape features}

The Pearson correlations between LST and endogenous landscape features showed both similarities and differences among the five cities (Fig. S7). LST was significantly correlated with NDBI_endo (positively) and Wetness_endo (negatively), and was insignificantly and inconsistently correlated with PV_endo and MNDWI_endo across all five cities, grain sizes, and neighbor sizes. The PV_endo LST correlations in Beijing, Changchun and Shanghai were significant and negative, and those in Chongqing and Changsha were mixed in both direction and significance across grain and neighborhood sizes. For example, the PV_endo LST correlations were significant and positive except grain size of $90 \mathrm{~m}$ in Chongqing, the PV_endo $\sim$ LST correlations were significant and negative until the grain size larger than $360 \mathrm{~m}$ in Changsha. Moreover, the MNDWI_endo LST correlations were significant and 
negative across all grain and neighborhood sizes in Chongqing, Changsha, and Shanghai while those in Beijing and Changchun became insignificant as the increase of grain and neighbor sizes. The Pearson correlations between LST and exogenous landscape features varied greatly across variables (e.g., max, mean, and range) and cities (Fig. S7). The signs of the maximum and mean values of exogenous landscape features (except MNDWI) to LST were in correspondence with those of endogenous landscape features, and LST was positively correlated with MNDWI_exo_max, and MNDWI_exo_mean across all five cities, grain sizes, and neighborhood sizes. In addition, the correlations of the range of exogenous landscape features were weaker than those of the maximum and mean values of exogenous landscape features. It implied that LST was mainly impacted by the absolute (average and highest) rather than relative (range or heterogeneity) conditions of neighbor landscape features, signifying the importance of proportion and evenness of exogenous landscape features to LST.

The partial correlation coefficients between LST and landscape features are shown in Fig. S8. First, some clear relationships emerged after controlling the effects of water bodies (MNDWI). The endogenous landscape features were all significantly correlated with LST regardless of grain and neighbor sizes. LST was negatively correlated with PV_endo and Wetness_endo, and the correlation coefficient of PV_endo was higher. NDBI_endo LST correlation was the strongest in all positive correlations. The correlations between exogenous landscape features and LST were 
consistent across cities, but became not significant when grain sizes increased. Most partial correlations of the exogenous variables of PV and Wetness to LST were negative, and the strongest and consistent performers among them were PV_exo_mean and Wetness_exo_range, respectively. The partial correlations of NDBI exogenous variables to LST were positive, and NDBI_exo_mean was the strongest performer. Second, when the effects of the PV, Wetness, and NDBI were controlled, the partial correlations between MNDWI_endo and LST were significantly negative in five cities. Moreover, the MNDWI_exo_mean $\sim$ LST was negative in all cities, but MNDWI_exo_max LST and MNDWI_exo_range LST correlations were mixed in sign and strength across grain and neighbor scales.

\subsection{LST sensitivity to landscape features}

Table S2 showed the manifested sensitivities of LST to endogenous landscape features resulted from OLS linear regressions. These sensitivities, defined as the increase (+) or decrease (-) in degrees of LST with every 0.1 increase in a given landscape feature index, varied greatly with city, grain size. For instance, LST sensitivities to PV_endo increased with grain size at varying speeds in different cities: from $-1.24{ }^{\circ} \mathrm{C}$ to $-1.87{ }^{\circ} \mathrm{C}$ in Beijing, from $-1.43{ }^{\circ} \mathrm{C}$ to $-2.26{ }^{\circ} \mathrm{C}$ in Changchun, from $0.79{ }^{\circ} \mathrm{C}$ to $-0.88{ }^{\circ} \mathrm{C}$ in Shanghai, from $0.02{ }^{\circ} \mathrm{C}$ (not significant) to $0.99{ }^{\circ} \mathrm{C}$ in Chongqing, and from $-0.31{ }^{\circ} \mathrm{C}$ to $0.17^{\circ} \mathrm{C}$ (not significant) in Changsha when grain size increased from $90 \mathrm{~m}$ to $900 \mathrm{~m}$. On the contrary, LST sensitivities to MNDWI_endo increased with grain size, from $-0.10{ }^{\circ} \mathrm{C}$ to $-0.07^{\circ} \mathrm{C}$ (not significant) in 
Beijing, from $-0.25{ }^{\circ} \mathrm{C}$ to $-0.90{ }^{\circ} \mathrm{C}$ (not significant) in Changchun, from $-3.44{ }^{\circ} \mathrm{C}$ to $4.49{ }^{\circ} \mathrm{C}$ in Shanghai, from $-2.10{ }^{\circ} \mathrm{C}$ to $-2.94{ }^{\circ} \mathrm{C}$ in Chongqing, and from $-1.12{ }^{\circ} \mathrm{C}$ to $1.18^{\circ} \mathrm{C}$ in Changsha when grain size increased from $90 \mathrm{~m}$ to $900 \mathrm{~m}$. It indicated that the small presence of water bodies had insignificant cooling effect in northern cities (i.e., Beijing and Changchun), but its large presence had strong cooling effect which could acutely pull down LST of non-vegetated areas in southern cities (i.e., Shanghai, Chongqing, and Changsha) (also see section 3.2). because the overwhelming cooling effect of water bodies could obscure the effect of other landscape features on LST, our subsequent analysis was only carried out in the grids without water bodies, following Chakraborty et al. (2019) and Yang et al. (2019), and the MNDWI representing water bodies was removed accordingly.

LST demonstrated consistency in direction (or sign) of intrinsic sensitivities to any given landscape feature across five cities when the effects of other landscape features were removed, as shown by the results from the ridge regression analysis (Fig. 3). However, the strength of LST intrinsic sensitivities to any landscape feature were different between five cities. The LST intrinsic sensitivities to NDBI_endo was the strongest in Changsha $\left(4.01^{\circ} \mathrm{C}\right)$, followed by Chongqing $\left(3.25^{\circ} \mathrm{C}\right)$, Changchun $\left(2.16^{\circ} \mathrm{C}\right)$, Beijing $\left(1.65^{\circ} \mathrm{C}\right)$, and Shanghai $\left(1.12{ }^{\circ} \mathrm{C}\right)$; the intrinsic sensitivity of LST to PV_endo decreased from Changchun $\left(-1.04{ }^{\circ} \mathrm{C}\right)$, Chongqing $\left(-0.84{ }^{\circ} \mathrm{C}\right)$, Beijing $(0.65$ $\left.{ }^{\circ} \mathrm{C}\right)$, Shanghai $\left(-0.44{ }^{\circ} \mathrm{C}\right)$ to Changsha $\left(-0.40{ }^{\circ} \mathrm{C}\right)$; the intrinsic sensitivity of LST to 
Wetness-endo decreased from Chongqing $\left(-1.49^{\circ} \mathrm{C}\right)$, Changsha $\left(-0.53{ }^{\circ} \mathrm{C}\right)$, Shanghai $\left(-0.51{ }^{\circ} \mathrm{C}\right)$, Beijing $\left(-0.44^{\circ} \mathrm{C}\right)$ to Changchun $\left(-0.37^{\circ} \mathrm{C}\right)$.

The intrinsic sensitivities of LST to PV_endo strongly and linearly correlated with those of LST to NDBI_endo across a range of grain and neighbor sizes in each city (Fig. 4). The slopes of the linear relationship indicate that the strongest offsetting effect of vegetation was found in Changchun (66\%), followed by Chongqing (56\%), Beijing (42\%), and Shanghai (41\%), and the weakest effect was in Changsha (not significant at $\mathrm{p}<0.05)$. Compared with the intrinsic sensitivities of LST to PV_endo, the intrinsic sensitivities of LST to Wetness_endo showed more diverse and weaker linear relationships with those of LST to NDBI_endo across cities. The slopes of the linear relationship were found insignificantly negative in Chongqing, Shanghai, and Changchun $(\mathrm{p}<0.05)$, and significantly positive in Beijing $(18.5 \%)$ and Changsha $(23.6 \%)$.

\subsection{Comparison and scaling of endogenous and exogenous landscape impacts}

Variance partitioning shows the collective impacts (i.e. total impact of all landscape features) of endogenous and exogenous landscape features on LST (Fig. 5). For simplicity, we will focus on the separate effects of endogenous and exogenous landscapes hereafter as their interactive effects were relatively small. It can be seen from Fig. 5 that the relative influences of endogenous and exogenous impacts on LST depend strongly on grain size and neighbor size. For example, the endogenous effect 
$\left(E_{\text {endo }}\right)$ was always lower than the exogenous effect $\left(E_{\text {exo }}\right)$ across all grid cell sizes from $90 \mathrm{~m}$ to $900 \mathrm{~m}$ when the neighbor size was $3 \times 3$ grid cells. However, this relationship changed with other neighbor sizes. For instance, $E_{\text {endo }}$ surpassed $E_{\text {exo }}$ with neighbor sizes of $5 \times 5,7 \times 7$ or $9 \times 9$ grid cells at the grain size of $630 \mathrm{~m}$.

Overall, the change of collective impacts of endogenous and exogenous landscape with grain size and/or neighbor size can be summarized by the following equations:

$$
\begin{aligned}
& E_{\text {endo }}=\beta \times n_{s} / g_{s}{ }^{0.5} \\
& E_{\text {exo }}=\gamma-\varepsilon \times n_{s}{ }^{0.5}
\end{aligned}
$$

where $g_{s}(\mathrm{~km})$ is grain size, $n_{s}(\mathrm{~km})$ is neighbor size, $\beta, \gamma$, and $\varepsilon$ are city-specific coefficients derived from nonlinear optimization (Table 1). The optimized parameter $\beta$ varied from 0.09 (Changsha) to 0.20 (Chongqing). The optimized parameters $\gamma$ and $\varepsilon$ ranged from 0.48 to 0.60 and from 0.12 to 0.31 across cities, respectively (Fig. 6 a, b). It can be seen from Eq. 10 that the endogenous effect is affected by both $g_{s}$ and $n_{s}$. Specifically, the endogenous effect increases linearly with $n_{s} / g_{s}^{0.5}$ (Eq. 10). At the same time, the exogenous influence declines nonlinearly with $n_{\mathrm{s}}^{0.5}$ (Eq. 11).

\section{Discussion}

\subsection{Demonstrated vs. intrinsic impacts of landscape features on LST}

Manifested LST sensitivity to landscape feature (i.e., LST change per unit change in a given landscape feature, and the effects of other features are not excluded) is one 
of the most frequently studied phenomena in UHI research (Guo et al., 2019; Zhang et al., 2009). Although it has long been observed, using manifested sensitivities, that increased building density could increase LST while increasing vegetation proportion or surface water content could effectively reduce LST (Connors et al., 2013; Rasul et al., 2015; Sun et al., 2012), our results of manifested LST sensitivities to landscape features do not necessarily support this general observation (Fig. S7 and Table S2).

For instance, the manifested sensitivity of LST to vegetation change is usually negative (Connors et al., 2013; Sun and Chen, 2017), but the manifested sensitivities in our analysis varied from negative (cooling impact) to positive (warming impact) across the five cities. Specifically, the LST manifested sensitivities to PV at the $900 \mathrm{~m}$ grain scale were all negative in Beijing, and Changchun, and Shanghai, but positive in Changsha and in Chongqing (Table S2). The existence of positive manifested sensitivities to PV suggests that increasing PV might generate a warming effect, conflicting with our conventional wisdom that vegetation tends to decrease the temperature in cities.

Would the increased PV really lead to higher LST, as suggested by the manifested sensitivities in Changsha and Chongqing? Subsequent partial correlation and ridge regression analyses revealed that this is not the case as shown by the intrinsic sensitivities of LST to PV (Fig. 3 and Fig. S8). In fact, analyses from both partial correlation (Fig. S8) and ridge regression (Fig. 3) show that LST intrinsic sensitivities to any given landscape feature (not just to PV), when water presence was controlled, 
was consistent across cities, which can be quite different from the results of Pearson correlation analysis. The discrepancy between results of Pearson correlation and partial correlation or ridge regression suggests that the inter-city variability of the Pearson correlation between LST and landscape features may be caused by the difference in hidden landscape features. For example, some cities have large flowing water bodies and some do not (Fig. S2, S3, and S5). In essence, cities are not simple combination of independent pieces but integration of many facets ${ }^{14}$, and the interplay of multiple landscape features can result in manifested sensitivities that are usually quite different from their corresponding intrinsic sensitivities. Manifested sensitivity represents the LST sensitivity to a given landscape feature with simultaneous influences of all other landscape components, not a suitable measure of the intrinsic LST sensitivity to a landscape feature. In consequence, it is very important to remove the confounding impacts of other factors when studying the sensitivity of LST to each landscape feature.

\subsection{The impacts of built-up, vegetation, and water on LST}

Intrinsic LST sensitivities demonstrated consistent patterns of landscape impacts on LST across cities (Fig. 3). First, as expected, the impacts of NDBI were positive while those of PV and Wetness were negative, suggesting built-up increases LST while vegetation and wetness subside it (Coutts et al., 2012; Gober et al., 2009; Myint et al., 2013; Skelhorn et al., 2014). Second, vegetation offsets a relatively constant fraction of the warming effect of built-up across a range of grain and neighbor sizes in 
each city, as indicated by the strong and negative relationships between intrinsic LST sensitivities to PV and NDBI (Fig. 4). The strongest offsetting effect of vegetation was found in Changchun (66\%), followed by Chongqing (56\%), Beijing (42\%), and Shanghai (41\%), and the weakest effect was in Changsha (Fig. 4). Such relatively constant offsetting percentages in each city shows that the stronger the heating effect of builds, the stronger the ameliorating effect from vegetation, a possible feedback mechanism that prevents urban LST from going up spirally and allows it to stay in livable ranges. In summary, the cooling effect generated by vegetation could offset $40 \%-60 \%$ of the heating effect of built-up. However, one outlier from the constant strong offsetting was found in Changsha where the offsetting effect varied in a nonsignificant narrow range.

Our study indicated that surface wetness (Wetness) can either intensify or mitigate the UHI effect. Significant positive relationship was found in Beijing and Changsha, suggesting wetness exacerbates the warming effect of built-up (Fig. 4). The additive heating impact of wetness to that of built-up was impressive in Changsha, which was higher than that in Beijing. At the same time, cooling (negative) effects, although not significant, were observed in Chongqing, Shanghai, and Changchun. The inconsistent regulatory power of surface wetness on the urban thermal environment across cities can be traced back to the diverse regulation mechanisms of wetness on temperature. Surface wetness plays a fundamental role in the reduction of LST through evapotranspiration (Rasul et al., 2015; Yang et al., 2013). However, too much surface 
wetness would lead to increase of moisture content in the atmosphere, which not only reduces incoming radiation but also warms up the air since water vapor is an efficient atmospheric greenhouse gas (Boucher et al., 2004; Sheng et al., 2017).

\subsection{The $1 / 2$ power scaling of the influences of endogenous and exogenous landscape features on LST in space}

Many studies have attempted to study the influences of endogenous and exogenous landscape features on LST (i.e., $E_{\text {endo }}$ and $E_{\text {exo }}$, respectively) (Feng and Myint, 2016; Sun et al., 2018; Zhang et al., 2017) and their scaling across spatial scales (Chun and Guldmann, 2014; Dai et al., 2019). For instance, Chun and Guldmann (2014) studied the relative strength of $E_{\text {endo }}$ and $E_{\text {exo }}$ in Columbus, $\mathrm{OH}$, USA using grain sizes ranging from $120 \mathrm{~m}$ to $480 \mathrm{~m}$, they found $E_{\text {exo }}$ values of solar radiation, sky view factor, and total NDVI were always smaller than their corresponding $E_{\text {endo }}$, and the difference of the two impacts increased with the grain size. Dai et al. (2019) found, $E_{\text {exo }}$ was larger than the $E_{\text {endo }}$ as grain size was within $180 \mathrm{~m}$ in Beijing, whereas, the opposite took place for larger grain size. However, most of previous studies only considered the effects of grain size without investigating the impacts of neighbor size and city specificity. Our study reveals that $E_{\text {endo }}$ and $E_{\text {exo }}$ are nonlinear functions of grain size $g_{s}$ and neighbor size $n_{s}$ (Eq. 10-11), independent of cities. Specifically, the $E_{\text {endo }}$ is affected by both the neighbor size $\mathrm{n}_{\mathrm{s}}$ and grain size $g_{s}$ in the form of $n_{s} / g_{s}{ }^{0.5}$, indicating that the $E_{\text {endo }}$ increases linearly with $n_{s}$ but nonlinearly constrained by $g_{s}$. Surprisingly, the $E_{\text {exo }}$ is only affected by 
neighbor size in the form of $-n_{s} 0.5$, suggesting that the exogenous influence declines nonlinearly with $n_{s}$.

\subsection{A 2/5 power scaling between grain size and neighbor size measures the relative strength of endogenous and exogenous influences on LST}

Understanding the relative strength of $E_{\text {endo }}$ and $E_{\text {exo }}$ and its change with grain and neighbor sizes are of critical importance to urban landscape design in light of UHI mitigation (Chun and Guldmann, 2014). It is necessary to understand under what conditions the endogenous and exogenous effects become equal to or larger than the exogenous effects. It is often perceived that when the grain size is small $E_{\text {exo }}$ would overwhelm $E_{\text {endo }}$; on the other hand, $E_{\text {exo }}$ would be negligible in comparison with $E_{\text {endo }}$ when the grain size is large. However, to our knowledge, no quantitative relationship exists prior to this study on how this relative strength of $E_{\text {endo }}$ and $E_{\text {exo }}$ changes with scales. The finding of the $1 / 2$ power scaling relationships of $E_{\text {endo }}$ and $E_{\text {exo }}$ brings this quantitative relationship into light.

To figure out the relative strength of $E_{\text {endo }}$ and $E_{\text {exo }}$, let us first find out the critical grain size $g\left(n_{s}\right)$ at which $E_{\text {endo }}$ equals to $E_{\text {exo }}$ (i.e., Eq. 10 equals to Eq. 11). The following relationship describing the critical $g\left(n_{s}\right)$ as a function of $n_{s}$ can be easily derived:

$$
g\left(n_{s}\right)=\left(\frac{\beta \times n_{s}}{\gamma-\varepsilon \times n_{s}{ }^{0.5}}\right) \quad \quad r
$$


This relationship suggests that, for a given $g_{s}, E_{\text {endo }}$ would be stronger than, equal to, or weaker than its exogenous counterpart $E_{\text {exo }}$ when $g_{s}<g\left(n_{s}\right), g_{s}=g\left(n_{s}\right)$, or $g_{s}>$ $g\left(n_{s}\right)$, respectively, for a given $n_{s}$. Equivalently, the critical neighbor size $n\left(g_{s}\right)$ as a function of $g_{s}$ can be derived similarly as follows:

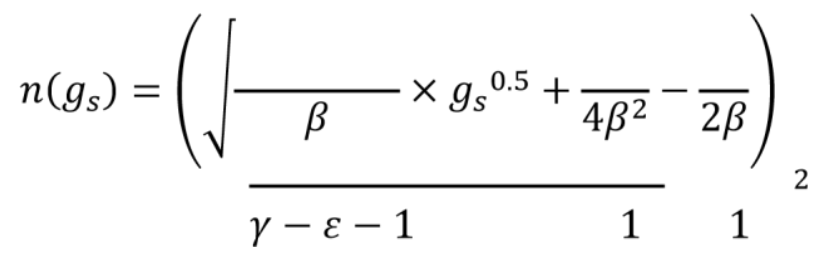

for a given $n_{s}, E_{\text {exo }}$ would be stronger than, equal to, or weaker than its endogenous counterpart when $n_{s}<n\left(g_{s}\right), n_{s}=n\left(g_{s}\right)$, or $n_{s}>n\left(g_{s}\right)$, respectively, for

given $g_{s}$. Fig. $6 \mathrm{c}$ shows all the city-specific equi-impact curves showing the equality of $E_{\text {endo }}$ and $E_{\text {exo }}$, plotted according to Eq. 13 with city-specific coefficients of $\beta, \gamma$, and $\varepsilon$.

The nonlinear change patterns of the equi-impact curves in the $n_{s}$ and $g_{s}$ spaces (Eq. 12 and 13) could be expressed by power functions or linear relationships in $\log \left(n_{s} / g_{s}\right)$ and $\log \left(g_{s}\right)$ spaces (Fig. 6d). As a result, the equi-impact curves in all these cities can be further represented by power functions with an exponent of $2 / 5$ as follows:

$$
n_{s}=\mathrm{kg} g_{s}^{2 / 5}
$$


Where $k$ is a city-specific constant. These equi-impact curves present a simple power scaling relationship between grain size and neighbor size that can be used to measure the relative strength of $E_{\text {endo }}$ and $E_{\text {exo }}$ : if $n_{s}>\mathrm{kg}_{s}{ }^{2 / 5}, E_{\text {endo }}>E_{\text {exo }}$; otherwise, $E_{\text {endo }}<E_{\text {exo }}($ Eq. 14). The k values derived from regression were 1.15, 1.36, 1.58, 1.78, and 3.01 for Beijing, Chongqing, Changchun, Shanghai, and Changsha, respectively.

The presence of the equi-impact curves suggests that the $\left(g_{s}, n_{s}\right)$ plane can be effectively partitioned into two regions (Eq. 12, Eq. 13 and Fig. 6c): the region above the curve where $E_{\text {endo }}>E_{\text {exo }}$ and the region below the curve where $E_{\text {endo }}<E_{\text {exo }}$. Following the equi-impact lines from the origin, we can find the turning point of $n_{s}$ growth rate occurred when $\mathrm{g}_{\mathrm{s}}$ is about $0.2 \mathrm{~km}$ : the increase speed of $n_{s}$ was much faster than that of $g_{s}$ before the turning point, and the disparity in the rates of change of $n_{s}$ and $g_{s}$ narrowed down gradually thereafter. This phenomenon shows that: (1) when the landscape patch is small, the influential neighborhood expands rapidly with the patch size, and (2) when the patch size is larger than $0.04 \mathrm{~km}^{2}$, the influential neighborhood tends to be stable.

The manipulation of the endogenous landscape to LST can only be realized in the area above the equi-impact line for a given city, since only when $E_{\text {endo }}>E_{\text {exo }}$ endogenous effects are considered to be manipulable. The manipulability of endogenous landscape varied across cities (Fig 6c, d) but follows the following descending order: Beijing, Chongqing, Changchun, Shanghai, and Changsha as indicated by the $k$ values in Eq. 14. Previous studies show that difference of 
manipulability may be caused by the heat transfer capacity varying from geographical backgrounds (Darmanto et al., 2017; Manoli et al., 2019; Yang et al., 2013). For instance, the much weaker regulation effect of landscape, especially vegetation and water body, on LST in Changsha, compared to other cities, might be explained by the fact that it is located in a closed basin surrounded by mountains on three sides and crossed by the Xiangjiang river, causing excessive air humidity that is not conducive to convection and heat evacuation (Yang et al., 2013). In contrast, stronger landscape control on LST in Chongqing, the most famous "mountain city" in China, may be attributed to the discontinuous landscape patterns within a complex terrain of mountains and valleys (Darmanto et al., 2017). However, the specific mechanisms behind the large inter-city variation are still unclear, and future research should focus on the effects of climate regime (Manoli et al., 2019), anthropogenic heat sources (Li et al., 2019c), and urban landscape characteristics such as buildings and canopy canyons (Li et al., 2019a; Ziter et al., 2019) .

\subsection{Implications on landscape design and future research}

In reality, the influence of landscape features can be manipulated via landscape design. Our study can potentially support landscape design in several areas. First, the sensitivities of LST to individual landscape features, particularly the intrinsic sensitivities, should provide guidance on the selection and layout of various features on landscape. The cooling effect generated by vegetation can offset $40 \%-60 \%$ of the heating effect of built-up, and wetness exacerbates the warming effect of built-up in 
some cities. Such relatively constant offsetting percentages in each city shows that there is a possible feedback mechanism that prevents urban LST from going up spirally. It also indicates that the cooling effect of vegetation at city level can be manipulated through changing vegetation coverage. For example, Changchun's cooling effect from vegetation (66\%) was higher than that in Beijing (42\%), which can probably be attributed to its higher vegetation or PV value (0.225) than that in Beijing (0.201) (Table S1). how to manipulate the colling effect of vegetation through changing landscape patterns is an important research topic but beyond the scope of our current study. Nevertheless, future research should focus more on exploring the impact of manipulating features on LST at the landscape scale using field-based approaches (Shaker et al., 2019) and/or high-resolution remotely sensed images (Dumke et al., 2018; Li et al., 2019b). Second, $E_{\text {endo }}$ depends on both $n_{s}$ and $g_{s}$ (Eq. 10). This implies that the impact strength of any land patch to itself LST is impacted not only by its own area but also by the area of its neighborhood. The scaling relationship of $E_{\text {endo }}$ (Eq. 11) suggests that when $g_{s}$ is large enough (its own landscape is relatively complete and independent), its interpretation power to focal LST remains relatively stable. When $n_{s}$ becomes too large, the exogenous influence to the focal LST will be reduced, so that LST is dominantly impacted by its own landscape. Third, $E_{\text {exo }}$ decreases nonlinearly with the increase of $n_{s}$ (Eq. 11). That is to say, no matter how large $g_{s}$ is, the impact of neighboring landscape to focal LST will be affected only by the area of its neighborhood, and the neighboring landscape influence will 
decrease with $n_{s}$. Fourth, manipulation of the relative strength of $E_{\text {endo }}$ and $E_{\text {exo }}$ can be realized by adjusting appropriate $n_{s}$ and $g_{s}$ (Eq. 13, Eq. 14). When urban planners want to optimize the local thermal environment, they should consider not only the local landscape, but also the corresponding scope of neighbor landscape, especially when $g_{s}$ is small, as suggested by the $2 / 5$ power scaling relationships of endogenous and exogenous impacts shown in this study.

In this study, we explored the sensitivity of LST to its own and the surrounding landscape characteristics and found some intriguing quantitative scaling relationships. Most previous studies only observed the variation of endogenous impacts with grain size (Rasul et al., 2015; Xiao et al., 2018), few have studied the relative change of the exogenous and endogenous impacts on grain and neighbor size (Chun and Guldmann, 2014). Future studies on the endogenous and exogenous effects of landscape features should include more geographically diverse cities. In particular, the variations of the city-specific coefficients $(\beta, \gamma, \varepsilon$, and $k$ in Eqs. 10, 11 and 14), their physical meanings and relationships with landscape features and/or regional climate regimes should be explored (Ramaswami et al., 2016; Ziter et al., 2019).

\section{Conclusions}

Understanding the influences of various landscape features on UHI and its dependence on spatial scale is critical for developing sustainable, and healthy cities. To investigate the influences of different landscape features on LST and how the features of a specific urban landscape (endogenous features), and neighboring 
environments (exogenous features) impact its LST across a continuum of spatial scales. We conducted a comparison study in five large cities (i.e., Beijing, Shanghai, Changsha, Chongqing, and Changchun) with very different climatic conditions across China, using different statistical approaches and analytical units with varied sizes.

Results show that (1) the cooling effect generated by vegetation could offset $40 \% 60 \%$ of the heating effect of built-up, while surface wetness intensifies or reduces it depending on climate conditions. Wetness generates cooling effects in Chongqing, Shanghai, and Changchun, and exacerbates the warming effect of built-up in Beijing and Changsha. (2) The influence of endogenous and exogenous landscape on LST can be described consistently across all cities as a nonlinear function of grain size $\left(g_{s}\right)$ and neighbor size $\left(n_{s}\right)$. In addition, a simple relationship describing the relative strength of endogenous and exogenous impacts of landscape features on LST was found ( $E_{\text {endo }}>$ $E_{\text {exo }}$ if $n_{s}>\mathrm{kg}_{s}^{2 / 5}$, where $k$ is a city-specific parameter; otherwise, $E_{\text {endo }}<E_{\text {exo }}$ ).

\section{Acknowledgments}

This work was supported by research grants from the National Natural Science Foundation of China (41971152) and Hunan Innovative Talent Program (2019RS1062) to SL, and the Ecology Program with funding from CSUFT, Hunan Province, China, the Scientific Innovation Fund for Post-graduates of CSUFT (CX20192065).

\section{References}

Anderson, M. and Cribble, N., 1998. Partitioning the variation among spatial, temporal and environmental components in a multivariate data set. Australian journal of ecology, 23(2): 158-167. 
Bai, X. et al., 2018. Six research priorities for cities and climate change. Nature Publishing Group.

Baig, M.H.A., Zhang, L., Shuai, T. and Tong, Q.J.R.S.L., 2014. Derivation of a tasselled cap transformation based on Landsat 8 at-satellite reflectance. 5(5): 423-431.

Behl, M. and Mangharam, R., 2016. Interactive analytics for smart cities infrastructures, 2016 1st International Workshop on Science of Smart City Operations and Platforms Engineering (SCOPE) in partnership with Global City Teams Challenge (GCTC)(SCOPE-GCTC). IEEE, pp. 1-6.

Best, M. and Grimmond, C., 2016. Investigation of the impact of anthropogenic heat flux within an urban land surface model and PILPS-urban. Theoretical and Applied Climatology, 126(1-2): 51-60.

Boucher, O., Myhre, G. and Myhre, A., 2004. Direct human influence of irrigation on atmospheric water vapour and climate. Climate Dynamics, 22(6-7): 597-603.

Chakraborty, T., Lee, X.J.I.J.o.A.E.O. and Geoinformation, 2019. A simplified urbanextent algorithm to characterize surface urban heat islands on a global scale and examine vegetation control on their spatiotemporal variability. 74: 269280 .

Chander, G., Markham, B.J.I.T.o.g. and sensing, r., 2003. Revised Landsat-5 TM radiometric calibration procedures and postcalibration dynamic ranges. 41(11): 2674-2677.

Chen, X.-L., Zhao, H.-M., Li, P.-X. and Yin, Z.-Y.J.R.s.o.e., 2006. Remote sensing image-based analysis of the relationship between urban heat island and land use/cover changes. 104(2): 133-146.

Chun, B. and Guldmann, J.M., 2014. Spatial statistical analysis and simulation of the urban heat island in high-density central cities. Landscape and Urban Planning, 125: 76-88.

Connors, J.P., Galletti, C.S. and Chow, W.T., 2013. Landscape configuration and urban heat island effects: assessing the relationship between landscape characteristics and land surface temperature in Phoenix, Arizona. Landscape ecology, 28(2): 271-283.

Connors, J.P., Galletti, C.S. and Chow, W.T.L., 2012. Landscape configuration and urban heat island effects: assessing the relationship between landscape characteristics and land surface temperature in Phoenix, Arizona. Landscape Ecology, 28(2): 271-283.

Coutts, A.M., Tapper, N.J., Beringer, J., Loughnan, M. and Demuzere, M., 2012. Watering our cities. Progress in Physical Geography: Earth and Environment, 37(1): 2-28. 
Crist, E.P., Cicone, R.C.J.I.T.o.G. and sensing, R., 1984. A physically-based transformation of Thematic Mapper data---The TM Tasseled Cap. (3): 256263.

Dai, Z., Guldmann, J.-M. and Hu, Y., 2019. Thermal impacts of greenery, water, and impervious structures in Beijing's Olympic area: A spatial regression approach. Ecological Indicators, 97: 77-88.

Darmanto, N.S., Varquez, A.C.G. and Kanda, M., 2017. Urban roughness parameters estimation from globally available datasets for mesoscale modeling in megacities. Urban Climate, 21: 243-261.

Dumke, I. et al., 2018. First hyperspectral imaging survey of the deep seafloor: Highresolution mapping of manganese nodules. 209: 19-30.

Dwivedi, A., Mohan, B.K.J.R.S.A.S. and Environment, 2018. Impact of green roof on micro climate to reduce Urban Heat Island. 10: 56-69.

Feng, X. and Myint, S.W., 2016. Exploring the effect of neighboring land cover pattern on land surface temperature of central building objects. Building and Environment, 95: 346-354.

Gautam, V.K., Gaurav, P.K., Murugan, P. and Annadurai, M., 2015a. Assessment of surface water Dynamicsin Bangalore using WRI, NDWI, MNDWI, supervised classification and KT transformation. Aquatic Procedia, 4: 739-746.

Gautam, V.K., Gaurav, P.K., Murugan, P. and Annadurai, M.J.A.P., 2015 b. Assessment of surface water Dynamicsin Bangalore using WRI, NDWI, MNDWI, supervised classification and KT transformation. 4: 739-746.

Geladi, P. and Kowalski, B.R., 1986. Partial least-squares regression: a tutorial. Analytica chimica acta, 185: 1-17.

Gober, P. et al., 2009. Using Watered Landscapes to Manipulate Urban Heat Island Effects: How Much Water Will It Take to Cool Phoenix? Journal of the American Planning Association, 76(1): 109-121.

Guha, S., Govil, H., Dey, A. and Gill, N.J.E.J.o.R.S., 2018. Analytical study of land surface temperature with NDVI and NDBI using Landsat 8 OLI and TIRS data in Florence and Naples city, Italy. 51(1): 667-678.

Guo, L. et al., 2019. Quantifying and simulating landscape composition and pattern impacts on land surface temperature: A decadal study of the rapidly urbanizing city of Beijing, China. Science of The Total Environment, 654: 430-440.

Huang, C., Wylie, B., Yang, L., Homer, C. and Zylstra, G., 2002. Derivation of a tasselled cap transformation based on Landsat 7 at-satellite reflectance. International journal of remote sensing, 23(8): 1741-1748. 
Jamei, Y., Rajagopalan, P. and Sun, Q.C., 2019. Spatial structure of surface urban heat island and its relationship with vegetation and built-up areas in Melbourne, Australia. Science of the total environment, 659: 1335-1351.

Kim, J.-P., 2013. Variation in the accuracy of thermal remote sensing. International journal of remote sensing, 34(2): 729-750.

Landauer, M., Juhola, S. and Klein, J., 2018. The role of scale in integrating climate change adaptation and mitigation in cities. Journal of Environmental Planning and Management, 62(5): 741-765.

Lee Rodgers, J. and Nicewander, W.A., 1988. Thirteen ways to look at the correlation coefficient. The American Statistician, 42(1): 59-66.

Li, D. et al., 2019a. Urban heat island: Aerodynamics or imperviousness? Science Advances, 5(4): eaau4299.

Li, H. et al., 2019b. Quantifying urban heat island intensity and its physical mechanism using WRF/UCM. 650: 3110-3119.

Li, R. et al., 2017. Simple spatial scaling rules behind complex cities. Nat Commun, 8(1): 1841.

Li, Y., Pizer, W.A. and Wu, L., 2019c. Climate change and residential electricity consumption in the Yangtze River Delta, China. Proc Natl Acad Sci U S A, 116(2): 472-477.

Manoli, G. et al., 2019. Magnitude of urban heat islands largely explained by climate and population. Nature, 573(7772): 55-60.

Muniz, G. and Kibria, B.G., 2009. On some ridge regression estimators: An empirical comparisons. Communications in Statistics - Simulation and Computation ${ }^{\circ}$, 38(3): 621-630.

Myint, S.W., Wentz, E.A., Brazel, A.J. and Quattrochi, D.A., 2013. The impact of distinct anthropogenic and vegetation features on urban warming. Landscape Ecology, 28(5): 959-978.

Nam, T. and Pardo, T.A., 2011. Smart city as urban innovation: Focusing on management, policy, and context, Proceedings of the 5th international conference on theory and practice of electronic governance, pp. 185-194.

Neinavaz, E., Skidmore, A.K., Darvishzadeh, R.J.I.J.o.A.E.O. and Geoinformation, 2020. Effects of prediction accuracy of the proportion of vegetation cover on land surface emissivity and temperature using the NDVI threshold method. 85: 101984.

Nill, L., Ullmann, T., Kneisel, C., Sobiech-Wolf, J. and Baumhauer, R.J.R.S., 2019. Assessing Spatiotemporal Variations of Landsat Land Surface Temperature 
and Multispectral Indices in the Arctic Mackenzie Delta Region between 1985 and 2018. 11(19): 2329.

O'brien, R.M., 2007. A caution regarding rules of thumb for variance inflation factors. Quality \& quantity, 41(5): 673-690.

Oke, T.R., 1982. The energetic basis of the urban heat island. Quarterly Journal of the Royal Meteorological Society, 108(455): 1-24.

Patz, J.A., Campbell-Lendrum, D., Holloway, T. and Foley, J.A., 2005. Impact of regional climate change on human health. Nature, 438(7066): 310-7.

Peres-Neto, P.R., Legendre, P., Dray, S. and Borcard, D., 2006. Variation partitioning of species data matrices: estimation and comparison of fractions. Ecology, 87(10): 2614-2625.

Pramanik, S. and Punia, M., 2019. Assessment of green space cooling effects in dense urban landscape: a case study of Delhi, India. Modeling Earth Systems and Environment, 5(3): 867-884.

Ramaswami, A., Russell, A.G., Culligan, P.J., Sharma, K.R. and Kumar, E., 2016. Meta-principles for developing smart, sustainable, and healthy cities. Science, 352(6288): 940-3.

Rasul, A., Balzter, H. and Smith, C., 2015. Spatial variation of the daytime Surface Urban Cool Island during the dry season in Erbil, Iraqi Kurdistan, from Landsat 8. Urban climate, 14: 176-186.

Rouse, J., Haas, R., Schell, J., Deering, D. and Harlan, J.J.T.A.U., Texas, 1974. Monitoring the vernal advancements and retrogradation.

Shaker, R.R., Altman, Y., Deng, C., Vaz, E. and Forsythe, K.W.J.J.o.c.p., 2019. Investigating urban heat island through spatial analysis of New York City streetscapes. 233: 972-992.

Sheng, L., Tang, X., You, H., Gu, Q. and Hu, H., 2017. Comparison of the urban heat island intensity quantified by using air temperature and Landsat land surface temperature in Hangzhou, China. Ecological Indicators, 72: 738-746.

Shi, P. et al., 2014. Climate change regionalization in China (1961-2010). Science China Earth Sciences, 57(11): 2676-2689.

Skelhorn, C., Lindley, S. and Levermore, G., 2014. The impact of vegetation types on air and surface temperatures in a temperate city: A fine scale assessment in Manchester, UK. Landscape and Urban Planning, 121: 129-140.

Sobrino, J.A., Jiménez-Muñoz, J.C. and Paolini, L.J.R.S.o.e., 2004. Land surface temperature retrieval from LANDSAT TM 5. 90(4): 434-440. 
Sun, Q., Wu, Z. and Tan, J., 2012. The relationship between land surface temperature and land use/land cover in Guangzhou, China. Environmental Earth Sciences, 65(6): 1687-1694.

Sun, R. and Chen, L., 2017. Effects of green space dynamics on urban heat islands: Mitigation and diversification. Ecosystem Services, 23: 38-46.

Sun, Y., Gao, C., Li, J., Li, W. and Ma, R., 2018. Examining urban thermal environment dynamics and relations to biophysical composition and configuration and socio-economic factors: A case study of the Shanghai metropolitan region. Sustainable cities and society, 40: 284-295.

Swamy, G., Nagendra, S.M.S. and Schlink, U., 2017. Urban heat island (UHI) influence on secondary pollutant formation in a tropical humid environment. J Air Waste Manag Assoc, 67(10): 1080-1091.

Taleghani, M., Crank, P.J., Mohegh, A., Sailor, D.J. and Ban-Weiss, G.A., 2019. The impact of heat mitigation strategies on the energy balance of a neighborhood in Los Angeles. Solar Energy, 177: 604-611.

Tang, J., Di, L., Xiao, J., Lu, D. and Zhou, Y., 2017. Impacts of land use and socioeconomic patterns on urban heat Island. International Journal of Remote Sensing, 38(11): 3445-3465.

Team, R.C., 2013. R: A language and environment for statistical computing. Vienna, Austria.

Theeuwes, N.E., Steeneveld, G.J., Ronda, R.J. and Holtslag, A.A., 2017. A diagnostic equation for the daily maximum urban heat island effect for cities in northwestern Europe. International Journal of Climatology, 37(1): 443-454.

Wang, Y. et al., 2019a. Tens of thousands additional deaths annually in cities of China between $1.5 \mathrm{C}$ and $2.0 \mathrm{C}$ warming. Nature communications, 10(1): 1-7.

Wang, Y., Zhan, Q. and Ouyang, W.J.S.o.t.T.E., 2019b. How to quantify the relationship between spatial distribution of urban waterbodies and land surface temperature? , 671: 1-9.

Xiao, H. et al., 2018. Responses of Urban Land Surface Temperature on Land Cover: A Comparative Study of Vienna and Madrid. Sustainability, 10(2).

Xu, D. and Guo, X.J.A.J.o.R.S., 2014. Compare NDVI extracted from Landsat 8 imagery with that from Landsat 7 imagery. 2(2): 10-14.

$\mathrm{Xu}$, H.J.I.j.o.r.s., 2006. Modification of normalised difference water index (NDWI) to enhance open water features in remotely sensed imagery. 27(14): 3025-3033.

Yang, Q., Huang, X. and Tang, Q.J.S.o.t.T.E., 2019. The footprint of urban heat island effect in 302 Chinese cities: Temporal trends and associated factors. 655: 652-662. 
Yang, W., Wong, N.H. and Zhang, G., 2013. A comparative analysis of human thermal conditions in outdoor urban spaces in the summer season in Singapore and Changsha, China. Int J Biometeorol, 57(6): 895-907.

Yu, X., Guo, X. and Wu, Z.J.R.s., 2014. Land surface temperature retrieval from Landsat 8 TIRS - Comparison between radiative transfer equation-based method, split window algorithm and single channel method. 6(10): 9829-9852.

Zha, Y., Gao, J. and Ni, S.J.I.j.o.r.s., 2003. Use of normalized difference built-up index in automatically mapping urban areas from TM imagery. 24(3): 583594.

Zhang, Y., Murray, A.T. and Turner, B.L., 2017. Optimizing green space locations to reduce daytime and nighttime urban heat island effects in Phoenix, Arizona. Landscape and Urban Planning, 165: 162-171.

Zhang, Y., Odeh, I.O. and Han, C., 2009. Bi-temporal characterization of land surface temperature in relation to impervious surface area, NDVI and NDBI, using a sub-pixel image analysis. International Journal of Applied Earth Observation and Geoinformation, 11(4): 256-264.

Zhou, D., Zhao, S., Liu, S., Zhang, L. and Zhu, C., 2014. Surface urban heat island in China's 32 major cities: Spatial patterns and drivers. Remote Sensing of Environment, 152: 51-61.

Zhou, J., Li, J., Zhang, L., Hu, D. and Zhan, W.J.I.J.o.R.S., 2012. Intercomparison of methods for estimating land surface temperature from a Landsat-5 TM image in an arid region with low water vapour in the atmosphere. 33(8): 2582-2602.

Zhou, W., Qian, Y., Li, X., Li, W. and Han, L., 2013. Relationships between land cover and the surface urban heat island: seasonal variability and effects of spatial and thematic resolution of land cover data on predicting land surface temperatures. Landscape Ecology, 29(1): 153-167.

Zhou, W., Wang, J. and Cadenasso, M.L., 2017. Effects of the spatial configuration of trees on urban heat mitigation: A comparative study. Remote Sensing of Environment, 195: 1-12.

Ziter, C.D., Pedersen, E.J., Kucharik, C.J. and Turner, M.G., 2019. Scale-dependent interactions between tree canopy cover and impervious surfaces reduce daytime urban heat during summer. Proc Natl Acad Sci U S A, 116(15): 75757580 . 


\section{Tables}

Table. 1 The parameter of Non-Linear System (NLS) regression to combined effects of endogenous $\left(E_{\text {endo }}\right)$, the formula is $E_{\text {endo }}=\beta \times n_{s} / g_{s}{ }^{0.5}$. And the parameter of NLS regression to combined effects of exogenous $\left(E_{\text {exo }}\right)$, the formula is $E_{\text {exo }}=\gamma-\varepsilon$ $\times n_{s} 0.5$.

\begin{tabular}{|c|c|c|c|c|c|c|c|}
\hline \multirow{2}{*}{ City } & \multicolumn{3}{|l|}{ Eendo } & \multicolumn{4}{|l|}{$E_{\text {exo }}$} \\
\hline & $\beta$ & RMSE & $\mathrm{R}^{2}$ & $\gamma$ & $\varepsilon$ & RMSE & $\mathrm{R}^{2}$ \\
\hline Beijing & $0.19^{* * *}$ & 0.09 & 0.80 & $0.52^{* * * *}$ & $0.30^{* * * *}$ & 0.05 & 0.90 \\
\hline Shanghai & $0.14^{* * *}$ & 0.07 & 0.72 & $0.48^{* * * *}$ & $0.18^{* * * *}$ & 0.04 & 0.80 \\
\hline Chongqing & $0.19^{* * * *}$ & 0.01 & 0.84 & $0.60^{* * * *}$ & $0.31^{* * * *}$ & 0.05 & 0.89 \\
\hline Changchun & $0.17^{* * * *}$ & 0.06 & 0.87 & $0.56^{* * * *}$ & $0.24^{* * * *}$ & 0.05 & 0.87 \\
\hline Changsha & $0.09^{* * * *}$ & 0.03 & 0.90 & $0.49^{* * * *}$ & $0.12^{* * * *}$ & 0.03 & 0.75 \\
\hline
\end{tabular}




\section{Figure Captions}

Fig. 1 Locations of the 5 major cities and six regions in China, with the background map indicating the topography of China.

Fig. 2 Grain and neighbor sizes used to characterize scale dependence of landscape features. a grain sizes, b neighborhood sizes.

Fig. 3 Heatmaps of ridge regression coefficients between landscape features and LST in five cities. Landscape features: PV, NDBI, MNDWI, and Wetness; endo and exo represent endogenous and exogenous, respectively; max, mean, and range represent the maximum, mean, and range values of exogenous landscape feature. The relationship between LST and landscape features was analyzed at various grain size ( $\mathrm{x}$ meters length scale) and neighbor size ( $\mathrm{m}$ by $\mathrm{m}$ cells), shown as LSTx_mm. The number of stars shows the significance level of coefficient, $* * * \mathrm{p}<0.001, * * \mathrm{p}<0.01, * \mathrm{p}<0.05$.

Fig. 4 Relationships between endogenous and exogenous effects of various landscape features on LST (i.e., ridge regression coefficients) in different cities across 16 spatial scales (each point represents a scale): PV_endo and NDBI_endo (green), and Wetness_endo and NDBI_endo (blue).

Fig. 5 The results of variance partitioning for endogenous and exogenous landscape features across scales (grid and neighborhood scale). a, b, c, d indicate neighbor size of $3 \times 3,5 \times 5,7$ $\times 7$, and $9 \times 9$ grid cells, respectively.

Fig. 6 Scaling and comparison of collective $E_{\text {endo }}$ and $E_{\text {exo }}$ across five cities. a The relationship between $E_{\text {endo }}$ predicted by Eq. 2 and $E_{\text {endo }}$ partitioned by variance partitioning. b The relationship between $E_{\text {exo }}$ predicted by Eq. 3 and $E_{\text {exo }}$ partitioned by variance partitioning. c The relationship between $E_{\text {endo }}$ and $E_{\text {exo }}$ in ns and $g_{s}$ spaces. d The relationship between $E_{\text {endo }}$ and $E_{\text {exo }}$ in $\log \left(n_{s} / g_{s}\right)$ and $\log \left(g_{s}\right)$ spaces. 
Fig. 1

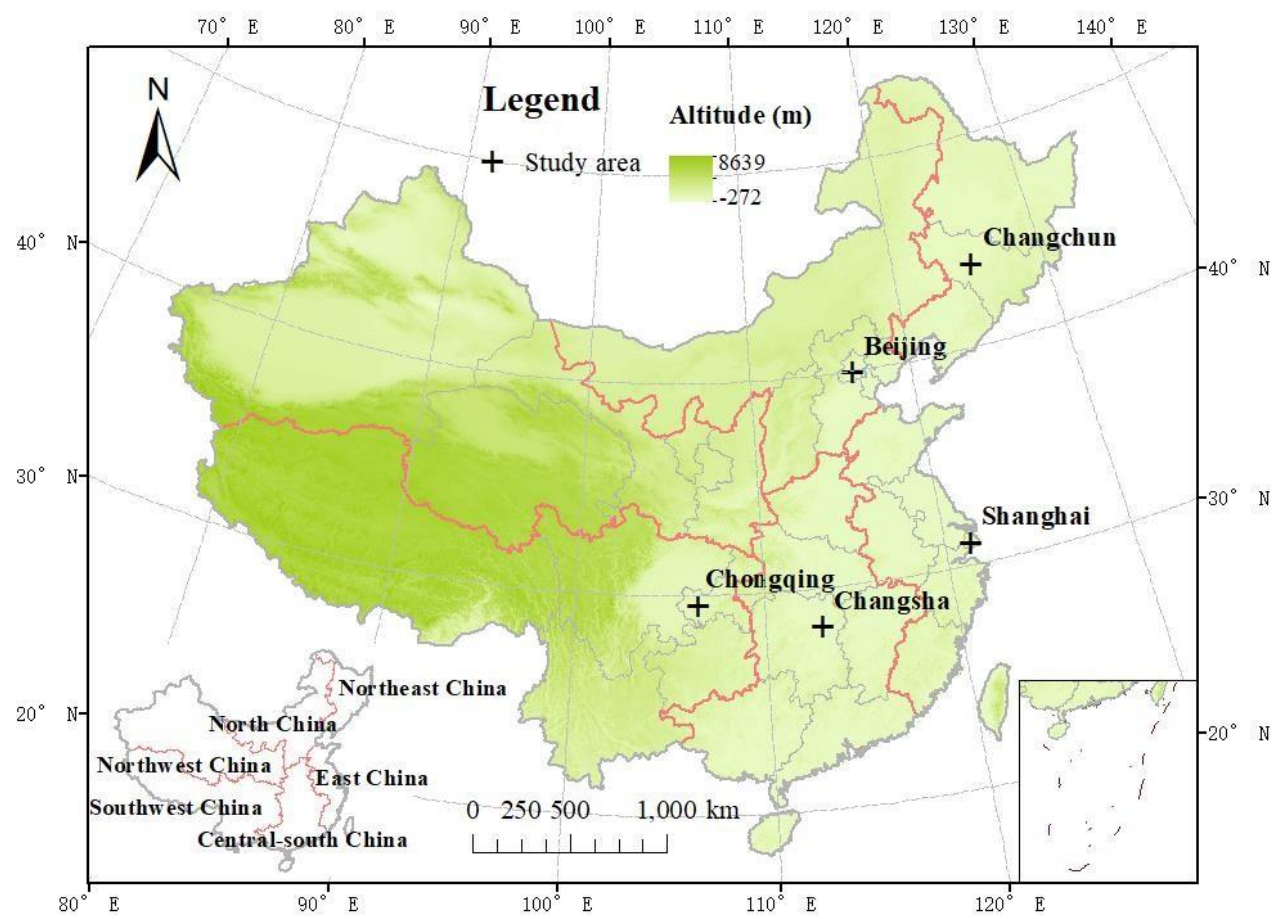

Fig. 1 Locations of the 5 major cities and six regions in China, with the background map indicating the topography of China.

Fig. 2

a
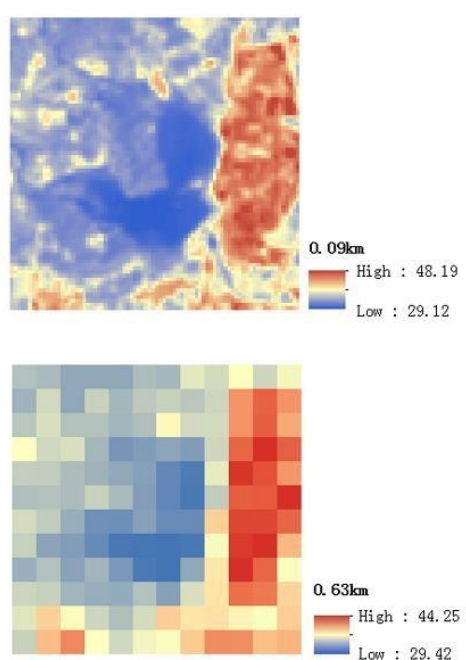
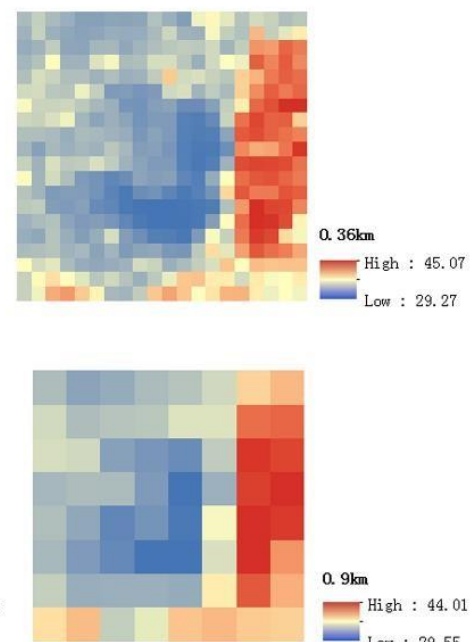

0. $9 \mathrm{~km}$

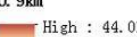

b

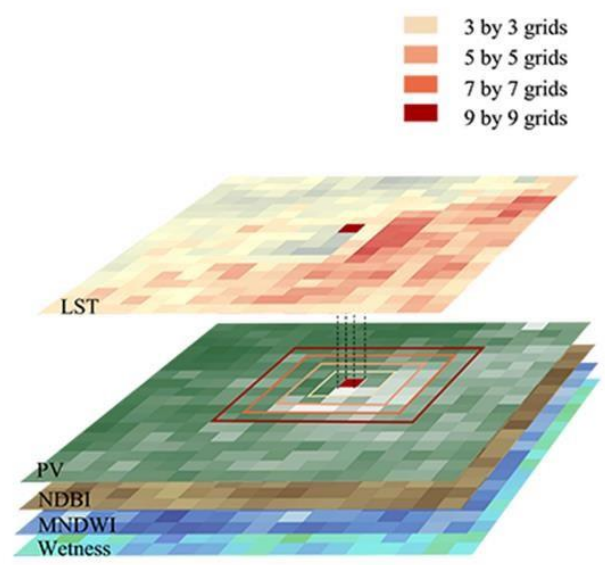

Fig. 2 Grain and neighbor sizes used to characterize scale dependence of landscape features. a grain sizes, $\mathbf{b}$ neighborhood sizes. 
Fig. 3

a

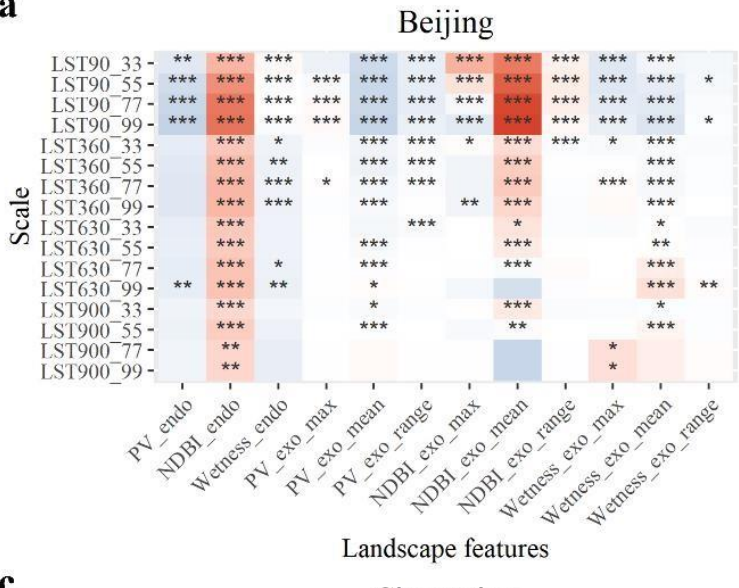

c

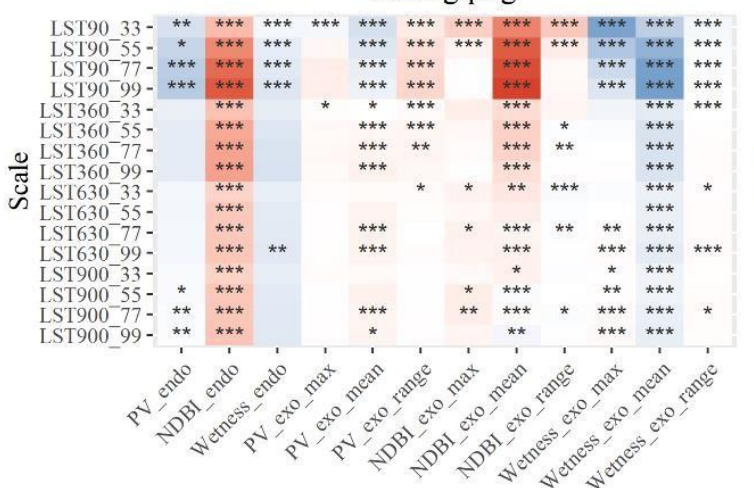

Landscape features

e

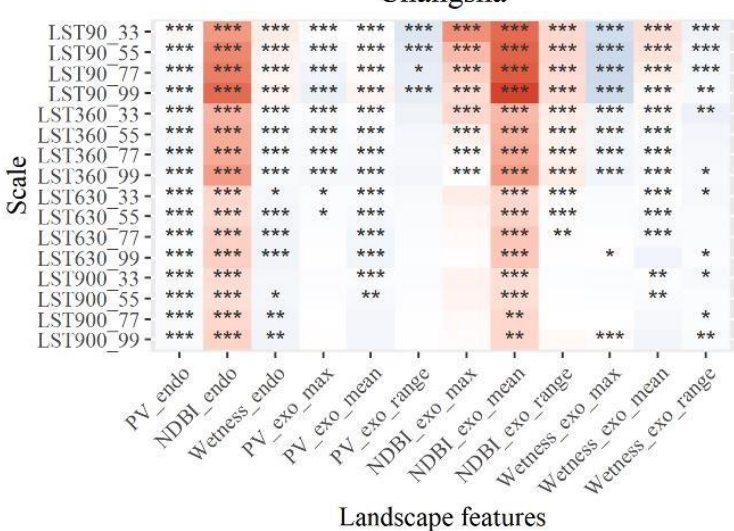

b
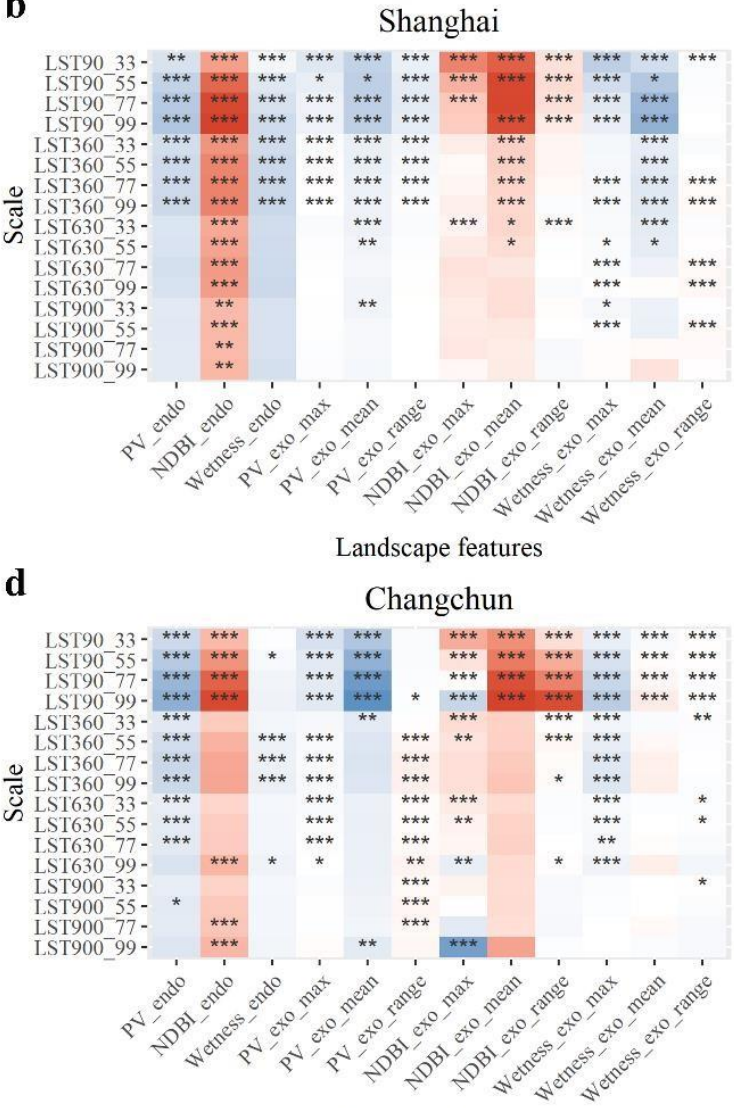

Landscape features

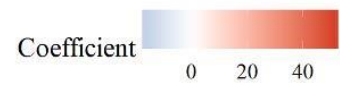

Fig. 3 Heatmaps of ridge regression coefficients between landscape features and LST in five cities. Landscape features: PV, NDBI, MNDWI, and Wetness; endo and exo represent endogenous and exogenous, respectively; max, mean, and range represent the maximum, mean, and range values of exogenous landscape feature. The relationship between LST and landscape features was analyzed at various grain size ( $\mathrm{x}$ meters length scale) and neighbor size ( $\mathrm{m}$ by $\mathrm{m}$ cells), shown as LSTx_mm. The number of stars shows the significance level of coefficient, $* * * \mathrm{p}<0.001, * * \mathrm{p}<0.01, * \mathrm{p}<0.05$. 
Fig. 4

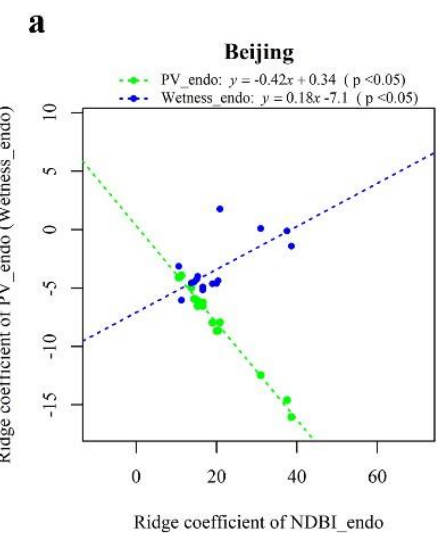

b

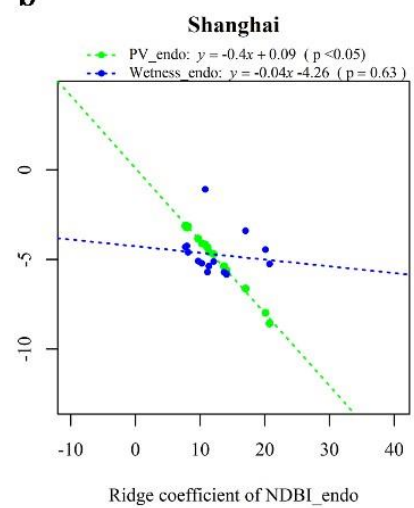

e Changsha
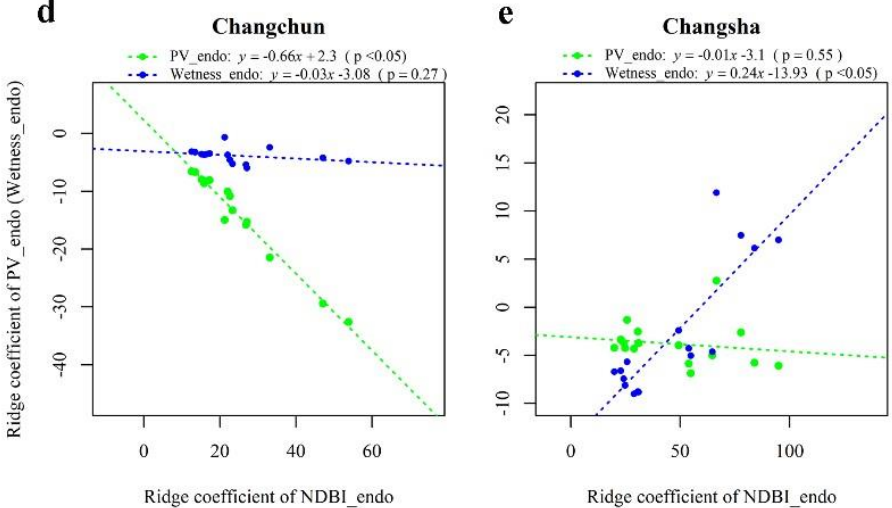

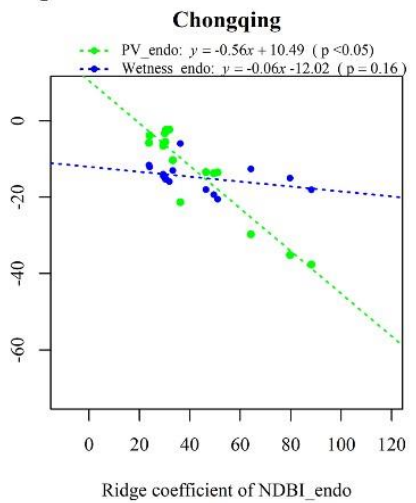

Ridge coefficient of NDBI_endo

Fig. 4 Relationships between endogenous effects of various landscape features on LST (i.e., ridge regression coefficients) in different cities across 16 spatial scales (each point represents a scale): PV_endo and NDBI_endo (green), and Wetness_endo and NDBI_endo (blue). 
Fig. 5

a

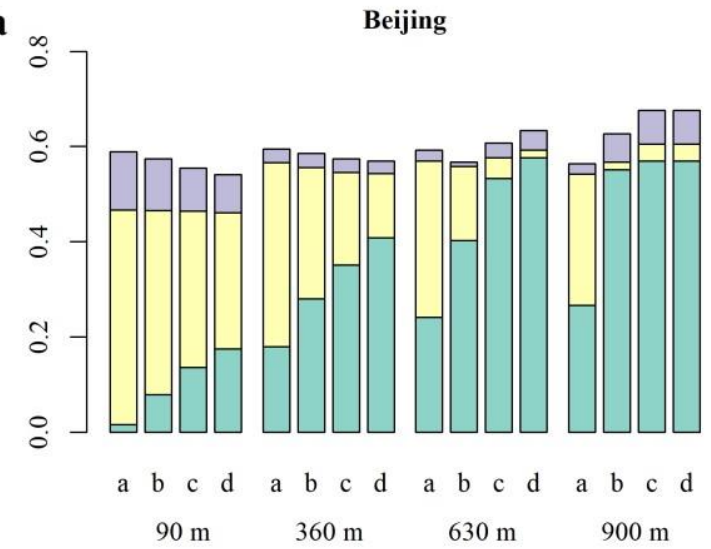

c

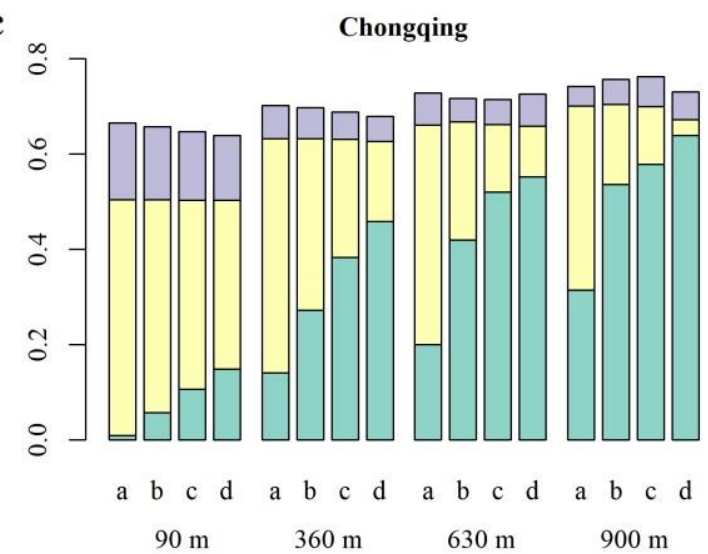

e

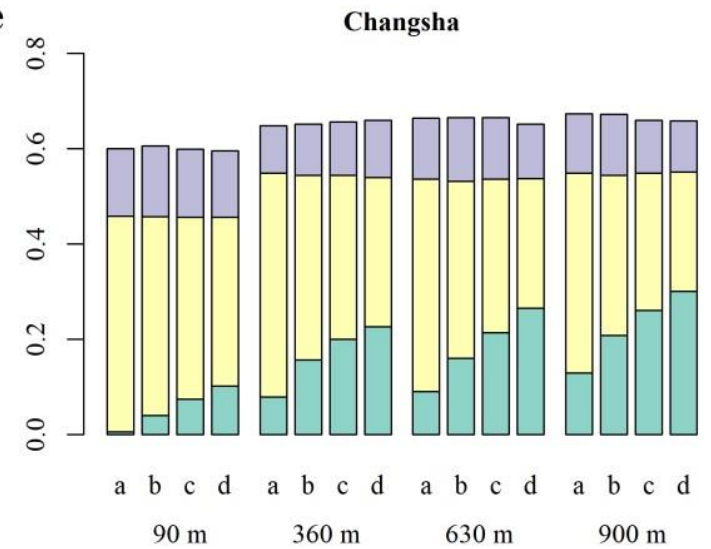

b

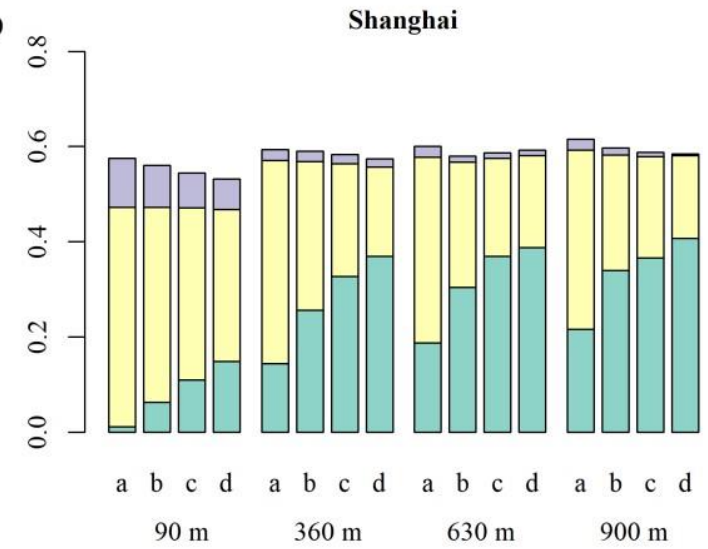

d

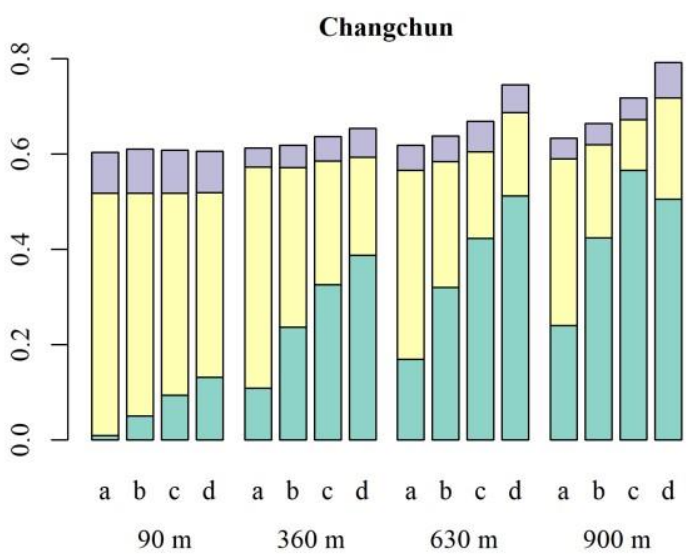

Fig. 5 The results of variance partitioning for endogenous and exogenous landscape features across scales (grid and neighborhood scale). a, b, c, d indicate neighbor size of $3 \times 3,5 \times 5,7 \times 7$, and $9 \times 9$ grid cells, respectively.

$\square$ effect of the endogenous features

$\square$ effect of the exogenous features

$\square$ joint effect of the endogenous and exogenous features 
Fig. 6

a
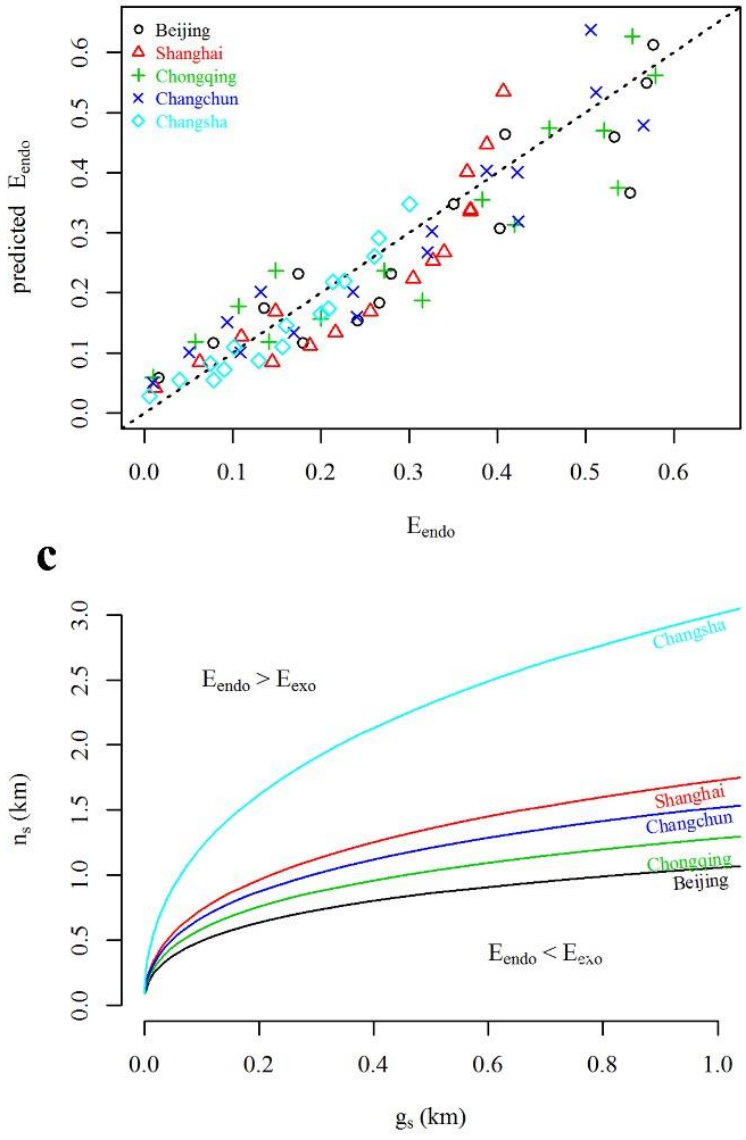

b

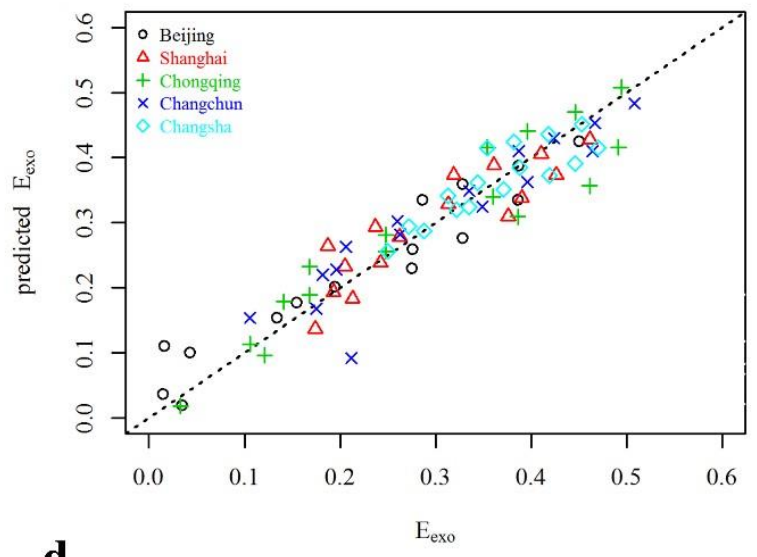

d

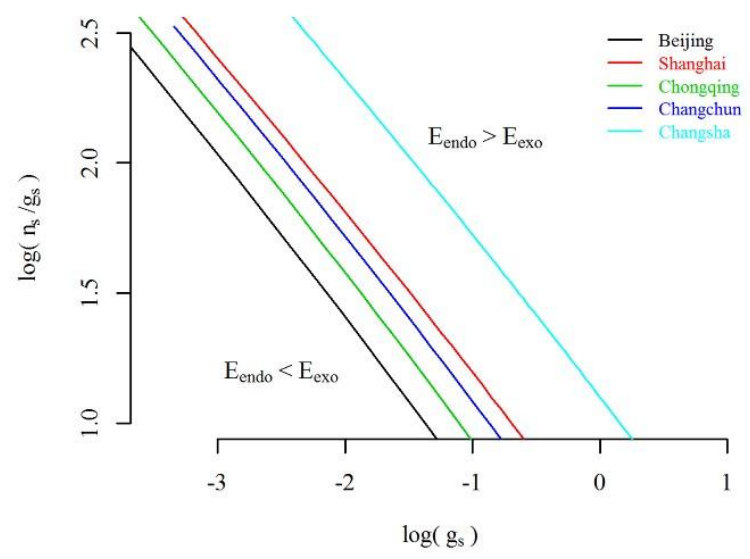

Fig. 6 Scaling and comparison of collective $E_{\text {endo }}$ and $E_{\text {exo }}$ across five cities. a The relationship between $E_{\text {endo }}$ predicted by Eq. 2 and $E_{\text {endo }}$ partitioned by variance partitioning. b The relationship between $E_{\text {exo }}$ predicted by Eq. 3 and $E_{\text {exo }}$ partitioned by variance partitioning. $\mathbf{c}$ The relationship between $E_{\text {endo }}$ and $E_{\text {exo }}$ in ns and $g_{s}$ spaces.d The relationship between $E_{\text {endo }}$ and $E_{\text {exo }}$ in $\log \left(n_{s} / g_{s}\right)$ and $\log \left(g_{s}\right)$ spaces. 